\title{
A EDUCAÇÃO DO CAMPO E A ESCOLA DO CAMPO: OCUPAÇÃO, LUTAS E CONQUISTAS NO ASSENTAMENTO PANA, MATO GROSSO DO SUL
}

\author{
Célia Beatriz Piatti (iD), José Roberto Rodrigues de Oliveira iD2, Bruna Carolina \\ de Oliveira Cardoso 3
}

Resumo: Neste artigo valemo-nos de atividades realizadas em dois projetos: no Projeto de extensão: "Do tempo de lona à conquista da escola: constituição e organização da memória social de assentamentos rurais e da Educação do Campo no Mato Grosso do Sul" e no Projeto de Pesquisa "Educação do Campo em Mato Grosso do Sul: escolas do/no campo construindo identidade". Para tanto, foram realizadas entrevistas com pessoas que participaram da ocupação de terras, viveram nos assentamentos e acampamentos, participaram da luta, resistiram aos conflitos e obtiveram conquistas. Para as entrevistas, os quatro participantes eleitos foram selecionados por terem participação na ação de ocupação, de resistência e posse da terra na região de Nova Alvorada do Sul, dando origem ao Projeto de Assentamento Nova Alvorada do Sul - PANA - lócus da pesquisa. As análises ancoram-se em uma perspectiva dialética pautada no método do Materialismo Histórico-Dialético. Considera-se importante afirmar que a escola está organicamente vinculada ao espaço onde está inserida, por isso é vital compreender os ideários da classe trabalhadora junto aos movimentos sociais em defesa do direito de todos os povos do campo à educação e, portanto, à escola de qualidade no campo.

Palavras-chave: Educação do Campo; Escola do Campo; Assentamento.

\section{FIELD EDUCATION AND FIELD SCHOOL: OCCUPATION, FIGHTS AND ACHIEVEMENTS IN THE PANA SETTLEMENT IN MATO GROSSO DO SUL}

Abstract: In this article we made use of activities carried out in two projects: in the Extension Project: "From canvas time to the conquest of school: constitution and organization of the social memory of rural settlements and Rural Education in Mato Grosso do Sul" and in the Project of Research "Rural Education in Mato Grosso do Sul: schools in / in the countryside building identity". To this end, interviews were conducted with people who participated in the occupation of land, lived in the settlements and camps, participated in the struggle, resisted the conflicts and obtained conquests. For the interviews, the four elected participants were selected for their participation in the occupation, resistance

\footnotetext{
${ }^{1}$ Doutora em Educação pela Universidade Federal de Mato Grosso do Sul (UFMS). Docente no curso de Licenciatura em Educação do Campo e no Programa de Pós-Graduação em Educação da UFMS. E-mail: celia.piatti@ufms.br.

${ }^{2}$ Doutorando em Educação pelo Programa de Pós-Graduação em Educação da Universidade Federal de Mato Grosso do Sul (UFMS). Docente do curso de Licenciatura em Educação do Campo da UFMS. E-mail: roberto.rodrigues@ufms.br.

${ }^{3}$ Licenciada em Educação do Campo pela Universidade Federal de Mato Grosso do Sul (UFMS). Professora da Educação Básica na Escola Estadual Antônio Coelho, em Nova Alvorada do SulMS. E-mail: brunacardoso20503@gmail.com.
} 
and land tenure action in the region of Nova Alvorada do Sul, giving rise to the Nova Alvorada do Sul Settlement Project - PANA - the locus of the research. The analyzes are anchored in a dialectical perspective based on the method of Historical-Dialectical Materialism. It is considered important to affirm that the school is organically linked to the space where it is inserted, so it is vital to understand the ideas of the working class together with social movements in defense of the right of all people in the field to education and, therefore, to the school of education. quality in the field.

Keywords: Rural Education; School of the Field; Settlement.

\section{Introdução}

$\mathrm{Na}$ perspectiva de reconhecer as lutas empreendidas para obtenção de terras, neste artigo busca-se compreender a ocupação, a luta e a resistência de uma população engajada por seus direitos no município de Nova Alvorada do Sul, em Mato Grosso do Sul, dentre eles o direito à escola. Para essa compreensão, valemo-nos de atividades realizadas em dois projetos, com suporte no Projeto de extensão4: "Do tempo de lona à conquista da escola: constituição e organização da memória social de assentamentos rurais e da Educação do Campo no Mato Grosso do Sul" e no Projeto de Pesquisa "Educação do Campo em Mato Grosso do Sul: escolas do/no campo construindo identidade". Para tanto, foram realizadas entrevistas com pessoas que participaram da ocupação de terras, viveram nos assentamentos e acampamentos, participaram da luta, resistiram aos conflitos e obtiveram conquistas.

Para as entrevistas, os quatro participantes eleitos foram selecionados por terem participação na ação de ocupação, de resistência e posse da terra na região de Nova Alvorada do Sul, dando origem ao Projeto de Assentamento Nova Alvorada do Sul - PANA - lócus da pesquisa. As análises ancoram-se em uma perspectiva dialética pautada no método Materialismo Histórico-Dialético, considerando a perspectiva Vigotskiana, que afirma que em uma investigação é necessário dar ênfase à análise do processo e não ao produto, da explicação para além da descrição e retornar à origem do fenômeno, uma vez que o objeto de pesquisa não é pronto, mas é necessário indagar rigorosamente para a sua compreensão em movimento, em tensão e em contradição.

No texto utilizam-se fotografias, pois elas ilustram os depoimentos e revelam a caminhada em busca de melhores condições de vida, de moradia, de trabalho, de educação e de construção de escolas que permitam às crianças, aos jovens e aos adultos do assentamento participarem da ação escolarizada na região em pauta.

Nesse sentido o artigo se compõe de seções em que se discutem: A educação do campo na escola do campo; o MST, a CPT engajados na luta por direitos; da ocupação à posse de terras em Mato Grosso do Sul; do tempo de Iona à conquista da escola.

${ }^{4} \mathrm{O}$ projeto de extensão foi coordenado pela professora Mariana Esteves de Oliveira -UFMS e o projeto de pesquisa é coordenado pela profa. Célia Beatriz Piatti-UFMS. 


\section{A educação do campo na escola do campo}

A Educação do Campo situa-se em um campo permeado por tensões e contradições constantes entre "[...] os interesses do Estado brasileiro, dos empresários e da sociedade civil organizada" (PIRES, 2012, p.81). Nessa tensão, a autora aponta que de um lado estão os movimentos sociais, os grupos organizados e a sociedade civil em luta por uma Educação que seja para a população do Campo, com qualidade advinda de políticas públicas como direito dos povos do campo.

Do outro lado, encontra-se o Estado brasileiro "[...] aportando uma legislação que, no período anterior a 1988, considerava a educação para a população do campo apenas numa ótica assistencialista ou de ordenamento social, ou seja, era a educação denominada "rural" (PIRES, 2012, p. 81). Nessa perspectiva, o grande desafio, conforme aponta Fernandes, Cerioli e Caldart (2009, p.23), "[...] é perceber qual educação está sendo oferecida ao meio rural e que concepção está presente nessa oferta".

Importante situar essas duas questões, ou seja, a concepção e a oferta, no sentido de compreender que essa educação precisa ser específica e diferenciada, mas sobretudo deve ser uma "[...] educação, no sentido amplo do processo de formação humana". (FERNANDES, CERIOLI; CALDART, 2009, p.23). Portanto, uma educação que seja de qualidade para a população do campo, voltada aos interesses do campo, na construção de uma escola com proposta educativa que valorize o projeto histórico dessa população.

Cabe ressaltar que "a escolarização não é toda educação, mas é um direito social a ser garantido" (FERNANDES, CERIOLI; CALDART, 2009, p.23). Desse modo, é necessário compreender a concepção de educação que está em pauta, assim como a sua oferta, o que nos faz buscar uma compreensão mais aprofundada da escola. Que escola queremos construir no campo e para a população do campo? Uma escola que favoreça o reconhecimento e o conhecimento dos interesses políticos, sociais, econômicos e culturais dos diferentes grupos e das formas de trabalhos que são produzidos no campo.

Essa escola precisa ser projetada a partir de uma constante transformação, conforme o desenvolvimento que acontece em seu espaço social. Dever ser uma escola com "[...] compromisso ético/moral com cada e de cada participante de nossas práticas educacionais; compromisso com a intervenção social; compromisso com a cultura do povo do campo (que implica resgate, conservação, recriação)" (FERNANDES, CERIOLI; CALDART, 2009, p.23).

Esses compromissos levam a reconhecer a população como sujeitos de direitos, dentre eles o direito à educação, à preservação dos saberes, da cultura, do respeito aos valores construídos e articulação com o projeto histórico com essa população e com o seu trabalho na terra.

Nesse sentido, as Diretrizes Operacionais para a Educação do Campo (2002), resguardam os ideais dos movimentos sociais do campo, os quais visam a uma organização de escola com propostas pedagógicas voltadas à realidade do espaço em que estão situados, levando em conta aspectos sociais, 
econômicos, políticos, culturais, de gênero, de etnia e de toda a diversidade existente nessa realidade.

É importante também trazer o que estabelece a Lei de Diretrizes e Bases da Educação Nacional (1996):

Art. 28. Na oferta de educação básica para a população rural, os sistemas de ensino promoverão as adaptações necessárias à sua adequação às peculiaridades da vida rural e de cada região, especialmente:

I - Conteúdos curriculares e metodologias apropriadas às reais necessidades e interesses dos alunos da zona rural;

II - Organização escolar própria, incluindo adequação do calendário escolar às fases do ciclo agrícola e às condições climáticas;

III - adequação à natureza do trabalho na zona rural. (BRASIL, 1996).

Com base na lei, há amparo na organização geral das escolas situadas no campo no que se refere a sua organização, mas há contradições na disposição dessas escolas, em um movimento que se apresenta frente à realidade de cada região, de cada secretaria de educação e de seus gestores.

Nesse sentido, é "[...] a escola que deve ajustar-se, em sua forma e conteúdo, aos sujeitos que dela necessitam; é a escola que deve ir ao encontro dos educandos e não o contrário". (CALDART, 2009, p.93).

Não há escolas do campo sem perspectivas com o povo sem horizontes e buscando sair dele. Por outro lado, também não há como implementar um projeto popular de desenvolvimento do campo sem um projeto de educação e sem expandir radicalmente a escolarização para todos os povos do campo. E a escola pode ser um agente muito importante de formação da consciência das pessoas para a própria necessidade de sua mobilização e organização para lutar por um projeto deste tipo. (CALDART, 2009. p.107)

Entende-se que, ao situar a escola do campo, é preciso considerar a participação dos movimentos sociais no campo como incentivadores dessa construção, pois eles propiciaram espaços interinstitucionais e instrumentos normativos para sua consolidação. Portanto: "A concepção de escola do campo nasce e se desenvolve no bojo do movimento da educação do campo, a partir das experiências de formação humana desenvolvidas no contexto de luta dos movimentos sociais camponeses por terra e educação". (MOLINA; SÁ, 2012, p. 324).

Uma escola com essas características coloca-se "[...] numa relação de antagonismo em relação às concepções de escola hegemônica e ao projeto de educação proposto para a classe trabalhadora." (MOLINA; SÁ, 2012, p. 324). Desse modo, requer reconhecer a escola do campo em uma relação orgânica com o campo, sua cultura e a sua identidade.

A escola pública é parte integrante da Educação do Campo, e esta a desafia na forma como é organizada historicamente. Desafia o ritual homogêneo e fragmentado da organização do trabalho pedagógico na escola. A educação do Campo precisa contemplar experiências escolares e não escolares que poderiam potencializá-las, em nome da transformação social em oposição à conservação. (PIRES, 2012, p.109). 
Oposição à conservação implica compreender a escola em seu espaço, isto é, compreender que a escola é o campo e o campo está na escola e ambos se encontram imbricados nas lutas, nos desafios e nas descobertas de suas potencialidades. Considera-se, a partir das ideias de Pires (2012), que pensar a escola do campo é não reduzi-la aos limites da escola, mas considerar o seu entorno, os diversos espaços e formas de educação.

Nesse sentido, é importante que a Escola do Campo tenha como meta os princípios que foram reafirmados no Decreto n.7.352/2010 em seu artigo $2^{\circ}$ :

Respeito à diversidade do campo em seus aspectos sociais, culturais, ambientais, políticos, econômicos, de gênero, geracional e de raça e etnia; Incentivo à formulação de projetos-políticos pedagógicos específicos para as escolas do campo, estimulando o desenvolvimento das unidades escolares como espaços públicos de investigação e articulação de experiências e estudos direcionados para o desenvolvimento social. Economicamente justo e ambientalmente sustentável, em articulação com o mundo do trabalho; Desenvolvimento de políticas de formação de profissionais da educação para o atendimento da especificidade das escolas do campo considerando-se as condições concretas da produção e reprodução social da vida no campo; valorização da identidade da escola do campo por meio de projetos pedagógicos com conteúdo curriculares e metodologias adequadas às reais necessidades dos alunos, bem como flexibilidade na organização escolar, incluindo adequação do calendário escolar às fases do ciclo agrícola e às condições climáticas; e controle social da qualidade da educação escolar, mediante e efetiva participação da comunidade e dos movimentos sociais do campo.

Esses princípios revelam a reconfiguração da identidade da escola do campo, com o seu caráter formativo e com o sentido real para atender as crianças e os jovens do campo no campo. Assim, construir a escola pública do campo é possibilitar a sintonia com os interesses dos povos do campo.

Considera-se que ancorar-se nesses princípios exige

[...] o rompimento com a lógica tradicional das escolas públicas. Trata-se de um movimento contraditório e de enfrentamentos entre concepção e projeto de sociedade e de educação. Portanto, não podemos afirmar que as escolas públicas são do campo porque elas são marcadas pela concepção da educação rural segundo a qual a instituição é determinada pelo Estado. (SOUZA; CRUZ, 2018, p.73).

A escola com a sua organização conservadora nem sempre possibilita romper com o modelo já instituído, o que prejudica com efeito a organização singular que uma escola do campo exige.

A escola é um espaço de disputas, o papel hegemônico do Estado acaba interferindo no processo educacional, pois reforça as relações capitalistas. A Educação do Campo está em constante movimento, e os sujeitos são construtores que lutam e resistem para transformar a realidade em que vivem (SOUZA; CRUZ, 2018, p.75).

Desse modo, entende-se que "A Educação do Campo não cabe em uma escola, mas a luta pela escola tem sido um de seus traços principais" (CALDART, 2004 , p. 36). Posto isso, cabe ressaltar que a escola do campo precisa "[...] 
explicitar os conflitos e as tensões decorrentes da construção de práticas educativas questionadoras da realidade social. A escola precisa apreender e intervir no contexto social, econômico e cultural em que está inserida" (PIRES, 2012, p.110). Sem essa compreensão do espaço da escola vinculado aos demais que se inserem no campo, será difícil a construção de uma escola que realmente seja do campo em toda a sua dimensão.

A escola do campo, em sua organização, tem a tarefa de possibilitar, dentro de sua função de escolarização, que os sujeitos nela inseridos possam se apropriar dos conhecimentos científicos historicamente produzidos pela humanidade, mas que compreendam também que a sua presença é fundamental para manutenção e ação da luta pela terra, por melhores condições de vida em um projeto de escola que se vincule organicamente ao projeto de sociedade e de transformação social.

\section{O MST, a CPT engajados na luta por direitos}

Se revisitarmos a história do Brasil, é possível afirmar que uma das origens dos movimentos sociais pode ser justificada pela ausência de políticas públicas que assegurassem os direitos de trabalhadores e trabalhadoras. Frente a essa ausência, grupos se organizaram como alternativa para lutarem coletivamente em busca desses direitos.

Direitos que esbarram em conflitos tensos no campo. Conflitos que foram relatados nos relatórios realizados pela Comissão Pastoral da Terra - CPT, em que foram destacados temas como terra, água, trabalho, violência e manifestações; e outros como despejos, expulsões, tempos de seca, áreas de garimpo, políticas públicas e sindicatos. Nesses relatórios, também se destacam as ações de resistência e enfrentamento que ocorrem no Brasil. De acordo Welch (2012):

A perspectiva da CPT segue sua vocação como protagonista e intermediária dos "trabalhadores e trabalhadoras do campo". Desses sujeitos, a organização registra uma diversidade de atividades econômicas, relacionando posseiros, assentados, remanescentes de quilombos, parceleiros, pequenos arrendatários, pequenos proprietários, ocupantes, sem-terras, seringueiros, quebradeiras de coco babaçu, castanheiros, faxinalenses etc. Nos "etc.", estão englobados assalariados, escravos, ribeirinhos, atingidos por barragens, pescadores, garimpeiros e grupos indígenas (WELCH,2013, p.142).

O autor segue afirmando que no relatório, em se tratando das manifestações, "[...] estão incluídos os movimentos socioterritoriais, tais como o movimento sindical rural, principalmente a Confederação Nacional dos Trabalhadores na Agricultura-Contag, e o Movimento dos Trabalhadores Rurais Sem Terra - MST, que lutam há décadas pela Reforma Agrária" (WELCH, 2013, p.142). O autor alerta que outros sujeitos essenciais para traçar os conflitos são os ruralistas, uma vez que "Os camponeses são protagonistas dos conflitos no campo hoje, mas só porque donatários, senhores de engenho, fazendeiros, 
grileiros, agroindustriais, agronegociantes e políticos ruralistas o foram ontem" (WELCH, 2013, p.142).

É possível vislumbrar que se não fossem as questões como a exploração do trabalho e a acumulação de terra, os camponeses não teriam motivos para se engajarem em conflitos históricos.

Conflitos no campo documentados pela CPT desde 1985 são novos capítulos de uma longa história. São os conflitos pela terra que demarcam a história do Brasil, determinando as transições políticas, sustentando ou derrubando governos, formando as classes sociais, selecionando os privilegiados e os marginalizados, estabelecendo os sistemas de dominação e resistência e deixando para a geração atual um punhado de memórias de vencedores e vencidos (WELCH, 2013, p.142).

Em grande parte, esses conflitos estão relacionados à questão agrária. O termo questão agrária é utilizado

Para designar uma área do conhecimento humano que se dedica a estudar, pesquisar e conhecer a natureza dos problemas das sociedades em geral relacionados ao uso, à posse e à propriedade da terra. Ao se fazer o estudo da forma de organização socioeconômica do meio rural de qualquer país, está-se estudando a questão agrária daquele país (STEDILE, 2013, p.639).

Segundo o mesmo autor, a origem da expressão vem dos primeiros estudiosos que, a partir do século XVIII e até o século $X X$, analisaram 0 desenvolvimento do modo de produção capitalista, ficando conhecidos como "pensadores clássicos" (STEDILE, 2013, p.639). Porém, o autor afirma que esse conceito como originalmente interpretado pelos pensadores clássicos evoluiu nas últimas décadas. Hoje, "há um entendimento generalizado de que a "questão agrária" é uma área do conhecimento científico que procura estudar, de forma genérica ou em Casos específicos, como cada sociedade organiza, ao longo de sua história, o uso, a posse e a propriedade da terra" (STEDILE, 2013, p. 642-643).

Estudos revelam que cada sociedade tem a sua forma de organização dos bens agrícolas e de uso da natureza.

Ao se estudar a questão agrária de determinada sociedade, em determinado período histórico, analisa-se como aquela sociedade organiza a produção dos bens agrícolas, a posse de seu território e a propriedade da terra. E, para cada aspecto estudado de cada sociedade em cada período histórico, serão encontrados diferentes "problemas agrários", surgidos como resultado das contradições criadas pelas formas de organização presentes naquela sociedade (STEDILE, 2013, p. 641).

É diante dessa questão que se impõem determinados movimentos sociais ávidos por lutar em grande parte pelo direito à terra, o qual traz como relação a própria existência de vida e de trabalho. Entre esses movimentos está o Movimento dos Trabalhadores Rurais Sem Terra - MST.

Segundo Fernandes (2013), o MST tem sido muito atuante na busca de seus objetivos de luta pela terra: 
Sua história está associada à luta pela Reforma Agrária e ao desenvolvimento do Brasil. Nasceu da ocupação da terra e se reproduz por meio da espacialização e da territorialização da luta pela terra. As conquistas de frações do território do latifúndio e a sua transformação em assentamento acontecem pela multiplicação de espaços de resistências e de territórios camponeses. Em cada estado onde iniciou a sua organização, o fato que registrou o seu princípio foi a ocupação (FERNANDES, 2013, p.496).

Nessa luta e ocupação, faz-se por direito a terra e consolida-se também a luta por direito à educação. Segundo Kolling, Vargas e Caldart (2013), a educação entrou na agenda do MST pela infância, isto é: "A necessidade do cuidado pedagógico das crianças dos acampamentos de luta pela terra, aliada a certa intuição das primeiras famílias em luta sobre serem a escola e o acesso ao conhecimento um direito de todos" (KOLLING; VARGAS; CALDART, 2013, p.500).

De acordo com Caldart (2009), olhando para a história do MST, é possível afirmar que, em sua trajetória, o movimento acabou fazendo uma verdadeira ocupação da escola, isso em três sentidos:

1.As famílias sem-terra mobilizaram-se (e mobilizam-se) pelo direito à escola e pela possibilidade de uma escola que fizesse diferença ou tivesse realmente sentido em sua vida presente e futura (preocupação com os filhos). As primeiras a se mobilizar foram as mães e professoras, depois os pais e algumas lideranças do movimento. 2. O MST, como organização social de massas, decidiu, pressionado pela mobilização das famílias e das professoras tomar para si ou assumir a tarefa de organizar e articular por dentro de sua organicidade esta mobilização, produzir uma proposta pedagógica específica para as escolas conquistadas e formar educadores e educadoras capazes de trabalhar nessa perspectiva.3. Podemos afirmar hoje que o MST incorporou a escola em sua dinâmica, e isto em dois sentidos combinados: a escola passou a fazer parte do cotidiano e das preocupações das famílias Sem Terra, com maior ou menor intensidade, com significados diversos, dependendo da própria trajetória de cada grupo, mas inegavelmente já consolidada com sua marca cultural: acampamento e assentamento dos sem-terra do MST têm que ter escola e, de preferência, que não seja uma escola qualquer; e a escola passou a ser vista como uma questão também política, quer dizer, como parte da estratégia de luta pela Reforma Agrária, vinculada às preocupações gerais do Movimento com a formação de seus sujeitos (CALDART,2009,p.92).

Frente a essa questão acerca da luta do MST também por escola encontrase a necessidade de pensar e fazer a escola no campo. Pensar no sentido de refletir sobre a sua existência no campo, tendo em vista as demandas dos trabalhadores do campo. Fazer no sentido de organizar a escola como marca desses trabalhadores, bem como de suas lutas, resistência e vitórias para o campo.

Há destaque também nessa caminhada a ação da CPT na defesa pelos direitos dos trabalhadores, sobretudo os sem-terra, em busca de lutas por quebra do latifúndio e, portanto, de Reforma Agrária. O trabalho dessa 
organização ${ }^{5}$ segue conforme a realidade e a necessidade de cada região e contexto. Sua luta constante é para que os trabalhadores tenham direito à terra e ao trabalho em condições dignas. Condições dignas significa também possibilidades de educação e de escolas para os filhos dos trabalhadores. Nesse sentido, a CPT

desenvolve sua ação junto dos homens e mulheres do campo em toda a sua diversidade: pequenos proprietários, agricultores familiares, agricultores sem-terra, camponeses e camponesas de diversos matizes quilombolas, ribeirinhos, extrativistas e outros muitos -, trabalhadoras e trabalhadores rurais assalariados, com atenção especial para os submetidos a condições análogas ao trabalho escravo (CANUTO, 2013, p. 128).

A missão da CPT "[...] se alicerça no clamor que vem dos campos e florestas, na memória subversiva do Evangelho e na fidelidade ao Deus dos pobres e aos pobres da terra. Ser uma presença solidária, profética, ecumênica, fraterna e afetiva, que presta um serviço educativo e transformador para os povos da terra e das águas" (CANUTO, 2013, p.129). Importante ressaltar o "[...] que a Comissão Pastoral da Terra nunca esqueceu é que ela existe como um serviço à causa dos trabalhadores e trabalhadoras e como um suporte para a sua organização" (CANUTO, 2013, p.130).

A CPT tem uma ação voltada às comunidades camponesas para que conquistem "[...] práticas, valores e direitos que promovam e defendam a vida dos seres humanos e do planeta Terra e que, ao mesmo tempo, garantam o protagonismo das populações camponesas e dos trabalhadores e trabalhadoras do campo (CANUTO,2013, p.132).

Pode se afirmar que esses grupos, entre outros, estão envolvidos junto aos camponeses com ações distintas, com ideologias às vezes distanciadas, mas com uma convergência: a de apontar caminhos na luta que se faz para conquistar a terra e dela viver. Por isso, a necessidade de compreender que "A terra não é só espaço de produção, mas lugar da vida; e, nesse espaço, devem ser desenvolvidas relações harmoniosas com a natureza e com todos os seres vivos que a habitam". (CANUTO,2013, p.132).

Soma-se a esse espaço de luta por terra, vida e trabalho, a luta por educação, a qual traz para os filhos dos trabalhadores sem-terra a possibilidade de ter escolas no campo que traçam rumos e que projetam espaço também de história desses trabalhadores e de garantia de seus direitos.

\section{Da ocupação à posse de terras em Mato Grosso do Sul}

As ocupações de terra são hoje a principal estratégia de ação coletiva adotada por movimentos sociais que lutam pela realização de uma reforma agrária no Brasil (ROSA, 2013, p.509). O autor afirma que o uso do termo

\footnotetext{
${ }^{5}$ Para reforçar a luta pelos direitos, a CPT criou um setor de documentação, o Centro de Documentação Dom Tomás Balduino, que registra os conflitos em que os homens e as mulheres do campo estão envolvidos e a violência que sofrem. Disponível em: https://cptnacional.org.br/. Acesso em: 18 abr. 2020.
} 
"ocupação de terras", no seu sentido contemporâneo, foi cunhado pelo MST. "O uso do termo ocupação foi estratégico na formulação das bases de justificação e legitimação do MST e na demanda pela realização da Reforma Agrária no Brasil" (ROSA, 2013, p. 509).

Rosa (2013, p.511) pondera que, ao usar o termo ocupação, "[...] o MST se refere ao direito constitucional de todo cidadão brasileiro de ter acesso à terra, conforme o Estatuto da Terra (Lei n.4.504, de 30 de novembro de 1964), o qual, em seu artigo 20 , assegurou a todos a oportunidade de acesso à propriedade da terra condicionada pela sua função social (BRASIL, 2004).

Pode se afirmar que a ocupação das terras sul mato-grossenses, como em outras regiões brasileiras, é caracterizada historicamente por conflitos violentos, marcados também pela resistência dos povos tradicionais e camponeses que lutaram e lutam contra a expulsão da terra. Em resistência e luta contra a agricultura capitalista, grupos compostos por camponeses e povos tradicionais lutam para conquistar a terra e outros direitos que muitas vezes a eles são negados.

Na luta pela terra, a ocupação é uma comprovação que o diálogo não é impossível. Ao ocupar a terra, os sem-terra vêm a público e iniciam as negociações, os enfretamentos com todas as forças políticas. Ao ocupar espaços políticos, reivindicam seus direitos. Quando o governo criminaliza essas ações, corta o diálogo e passa dar ordens. Tenta destruir a luta pela terra sem fazer a Reforma Agrária (FERNANDES, 2001, p. 36).

Para Mello (2015, p.133), em Mato Grosso do Sul, "[...] a questão agrária tem sua origem no processo de apropriação capitalista da terra ocorrido por meio de leis e políticas que permitiram a grilagem e a concentração fundiária no Estado. Os problemas sociais no campo se agravaram com a intensificação do atual modelo de agricultura capitalista, denominado de agronegócio6, com origem na Revolução Verde7, na década de 1970".

Frente a esse quadro, Mello (2015, p.143), tendo em vista o relatório da CPT (1994), aponta que:

Em Mato Grosso do Sul, o início da organização do MST está ligada à ocupação da gleba Santa Idalina, no município de Ivinhema (MS), em abril de 1984, com cerca de 1500 famílias participando da ação. Essa ocupação marcou a luta pela terra no estado de MS por conta dos conflitos entre trabalhadores e a polícia e por dar início a organização de camponeses e trabalhadores rurais em movimentos socioterritoriais.

Ancorado nas ideias de Fernandes (2000), Melo (2015) alerta que se utiliza o conceito de movimento socioterritorial quando se refere aos movimentos em

\footnotetext{
${ }^{6}$ Agronegócio: Termo que expressa as relações econômicas (mercantis, financeiras e tecnológicas) entre o setor agropecuário e aqueles situados na esfera industrial (tanto de produções destinados à agricultura quanto de processamento daqueles com origem no setor), comercial e de serviços (LEITE; MEDEIROS, 2013, p.79).

${ }^{7}$ Revolução verde: Introdução de variedades modernas de alta produtividade em larga escala, a partir da década de 1950, em muitos países do mundo, inclusive no Brasil (COX; PEREIRA, 2013, p.685).
} 
Mato Grosso do Sul que lutam pela terra e pelo território, pois parte-se do pressuposto que "[...] movimentos socioterritoriais são todos os que têm o território como trunfo. [...] Um movimento socioterritorial como o MST tem como um de seus principais objetivos a conquista da terra e de trabalho. E os realiza por meio de uma ação denominada ocupação da terra" (FERNANDES, 2000, p.59).

A ocupação da gleba Santa Idalina, no município de Ivinhema em Mato Grosso do Sul, tornou-se um marco para a história da luta pela terra na região, como mostra a seguinte declaração advinda de relatórios da CPT:

A ocupação de Idalina constitui-se num marco histórico da mobilização dos Trabalhadores Rurais Sem terra na luta pela terra. Desencadeiam-se a partir daí, nos anos seguintes, [...] ocupações e acampamentos com maior ou menor organização dos mesmos. Somente para ilustrar, é significativo o número de cartas de apoio e solidariedade que o movimento recebeu durante os meses de maio e junho. Aproximadamente 180 cartas e telegramas, de várias entidades ligadas às lutas populares de quase todos os Estados brasileiros de Norte a Sul, solidarizando-se com os ocupantes de Ivinhema (CPT, 1994, p.95).

Entre outras ocupações realizadas após a de Santa Idalina está a do Assentamento Projeto de Assentamento Nova Alvorada do Sul - PANA. Em meados de 1993, algumas famílias da região de Mato Grosso do Sul (Fátima do Sul, Vicentina e Jatei) se organizaram em busca da Reforma Agrária, inicialmente sob a orientação do MST. Posteriormente, algumas famílias passaram a receber orientações também da CPT. Cabe ressaltar que as relações com o MST não foram lineares, como sugere a entrevista colhida para a pesquisa:

Nós nos desligamos do MST, montamos um grupo da CPT, nos organizamos no salão da igreja São Francisco, no fim de 1993 e formamos um grupo. Fomos fazer uma ocupação na fazenda Santa Virgínia, município de Bataiporã, onde nós não tínhamos conhecimento, não tínhamos organização, não sabíamos bem como funcionava, pouco conhecimento. E os Jagunços estavam nos esperando, mas Deus foi tão bom que os carros quebraram na estrada e amanheceu o dia e os Jagunços desistiram e mesmo assim nós persistimos, entramos na fazenda de dia. Nós entramos por volta do meio-dia e a tarde o fazendeiro organizou o pessoal e nos colocou para voltar (ENTREVISTADO 1).

O entrevistado 1 explica que os grupos se desligaram do MST por julgarem que muitas ações do movimento não traduziam as suas ideias. Nesse caminho, após a tentativa malsucedida de ocupação em Bataiporã, em Mato Grosso do Sul, as famílias dirigiram-se para o município de Jateí-MS, onde montaram acampamento, mas não obtiveram sucesso. Em 1994, sob orientação da CPT, as famílias foram informadas sobre a situação em que se encontrava a fazenda PAM (Paulo Afonso Meneghel), em que hoje se localiza o assentamento PANA.

$\mathrm{Na}$ fazenda, produzia-se cana-de-açúcar para o abastecimento da usina de álcool denominada Destilaria Rio Brilhante, que deixou de funcionar em 1991 e que, segundo o depoimento dos assentados, encontrava-se em estado de total 
abandono: "Na verdade estava tudo abandonado, tinha mato, aquela cana bem rala mesmo, a usina estava desativada, aí nós acampamos lá na beira do Sal Amargo, beira de um córrego, ficamos acampados na área uns 15 dias. Mas era totalmente abandonado" (ENTREVISTADO 1).

Após o reconhecimento da área, as famílias montaram acampamento às margens do córrego Sal Amargo, um dos afluentes do Rio Vacaria de onde saíram após algum tempo, acampando novamente na BR 145, às margens do Rio Branco, onde permaneceram quase três anos à espera da desapropriação, como mostra a imagem cedida pelo entrevistado.

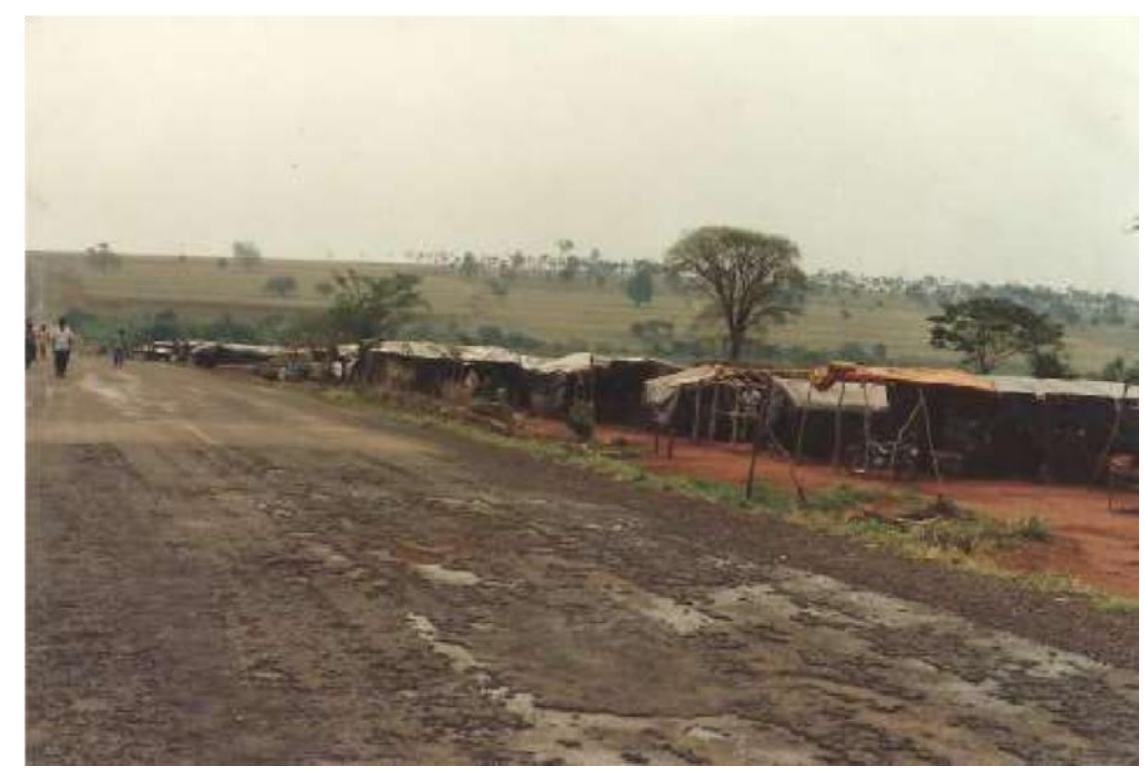

Figura 1: Acampamento às margens da BR 145, em meados de 1994. Fonte: Entrevistado 1.

Durante as entrevistas, foi questionado aos assentados a respeito de suas lembranças do "tempo de lona", e em cada relato, com brilho nos olhos e orgulho nas palavras, eles nos revelaram os momentos de luta pelos quais passaram: a repressão, a descriminação, a dificuldade de locomoção, a falta de emprego, a luta pela escola no acampamento, entre outras barreiras que foram vencidas através da união dos acampados. "Nossa dificuldade foi que no começo não tinha escola, logo no começo não tinha serviço porque as pessoas não confiavam porque era acampamento, então os fazendeiros não queriam arrumar serviço. Dificuldade financeira, era muito longe da cidade, os jovens iam estudar no Ipezal, em cima de uma camionete" (ENTREVISTADO3).

Uma questão importante foram as reuniões que, em sua organicidade, promoviam debates e discussões que possibilitavam a união do grupo para a conquista da empreita que buscavam, conforme apresenta a imagem 2 e o depoimento do entrevistado. "Todo mundo trabalhava e tinha união. Acreditavam na liderança, acreditavam e tinham aquela fé que iam conquistar o pedaço de terra deles (ENTREVISTADO 1 ).

A imagem 2 e o depoimento mostram como a organização e a união fortaleceram a luta e a possibilidade de resistir às intempéries e alcançar o 
objetivo e o direito de buscar as condições de vida que favorecessem as famílias que residiam nos acampamentos.

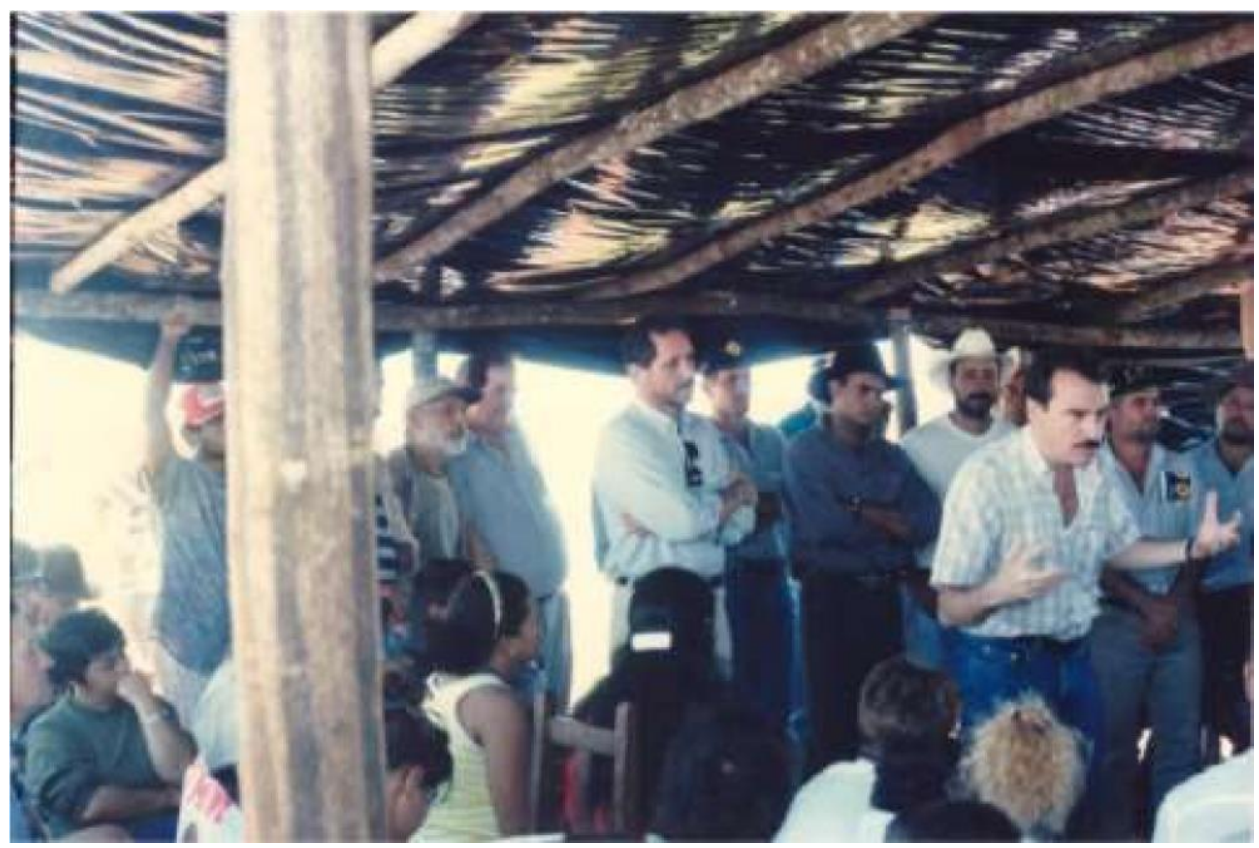

Figura 2: Acampados em reunião (1996).

Fonte: Arquivo de Manoel Francisco Alves.

A dificuldade financeira era um aspecto que influenciava diretamente a vida dos acampados, os quais passaram necessidades por diversas vezes devido à falta de alimentação, roupas e calçados, como nos mostra os seguintes relatos: "Então eu me lembro de muitas passagens difíceis e principalmente um dia que, lá em Rio Brilhante, que eu não tinha arroz, não tinha feijão, eu tinha unicamente uma abóbora, porque eu ganhei de um homem chamado Dirceu [...] Aí eu fiz aquela abóbora e nós comemos na janta, foi a nossa janta" (Entrevistado 1).

Foram muitas dificuldades e desafios para conquistar a terra para viver, para conseguir trabalhar, sustentar a família como mostra o relato do entrevistado 4.

Foram muitas dificuldades, porque são 150 km de Fátima do Sul e aí, como a gente pegou todo o pessoal de Fátima do Sul, Vicentina, Dourados, Rio Brilhante, então vinha gente de toda a região, então para esse povo se locomover era difícil. Tem uns companheiros que estão até hoje aqui com a gente, que pegaram terra, e tinham dois caminhões, então a gente andava tipo pau de arara, muita gente de pé naquele caminhão, tinham caminhões assim que levava 80,90, 100 pessoas. Todos de pé, um segurando no outro, para poder se acampar, às vezes para fazer compra mesmo, porque tinha na época da agricultura o pessoal que estava nos acampamentos que saíam para trabalhar, no fim da semana recebiam e iam para a cidade mais próxima (ENTREVISTADO 1).

Mas mesmo frente às dificuldades, não havia a falta de esperança; a fé, a crença permitia-Ihes momentos de oração. Os acampados realizavam suas práticas religiosas no barracão de assembleia do acampamento, conforme depoimento e imagem 3. 
Aos domingos, quando a gente estava acampado, era assim, não tinha divisão de religião. Então tinha um barracão, que era o barracão da assembleia onde se faziam as reuniões, num domingo era a igreja católica que fazia as orações, dirigia e aí todos participavam. Aí, no outro domingo, era o pessoal da igreja Assembleia de Deus, todos participavam (ENTREVISTADO 4).

A imagem 3, assim como o depoimento do entrevistado revelam que eles eram unidos em todos os aspectos no sentido de reunir forças para conquistar um projeto em que todos estavam envolvidos.

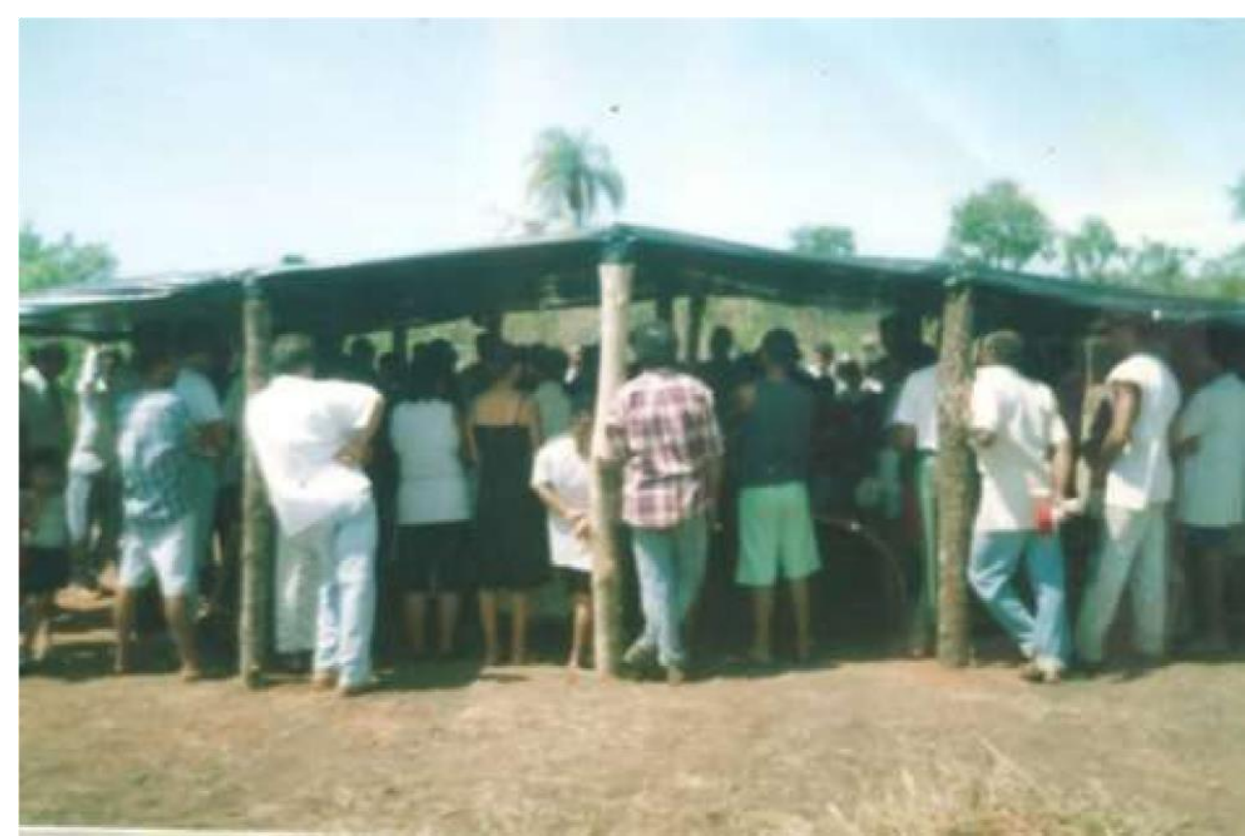

Figura 3: Barracão para oração.

Fonte: Arquivo de Manoel Francisco Alves.

Frente às dificuldades pelas quais passaram, após várias ocupações e reocupações durante anos de luta, as terras foram finalmente desapropriadas e divididas. O sorteio foi realizado no dia 27 de janeiro de 1997. Foram sorteados 86 lotes e 72 residências da Agrovila onde moravam os antigos funcionários da usina.

O sorteio foi reconhecido pelo Instituto Nacional de Colonização e Reforma Agrária Incra, no dia 12 de maio de 1997. Um dia de comemoração como revela a imagem 5 e recorda o entrevistado. "O mais gostoso foi quando saiu o decreto, que tinha aquele pessoal que fazia muita promessa, então foi assim praticamente dois dias de festa. Tinha muita gente que ficou quase o dia todo, a noite toda, de joelhos agradecendo promessas que eles tinham feito; outros faziam orações, outros cantavam, muitas coisas gostosas que ficaram gravadas na nossa mente" (ENTREVISTADO 1). 


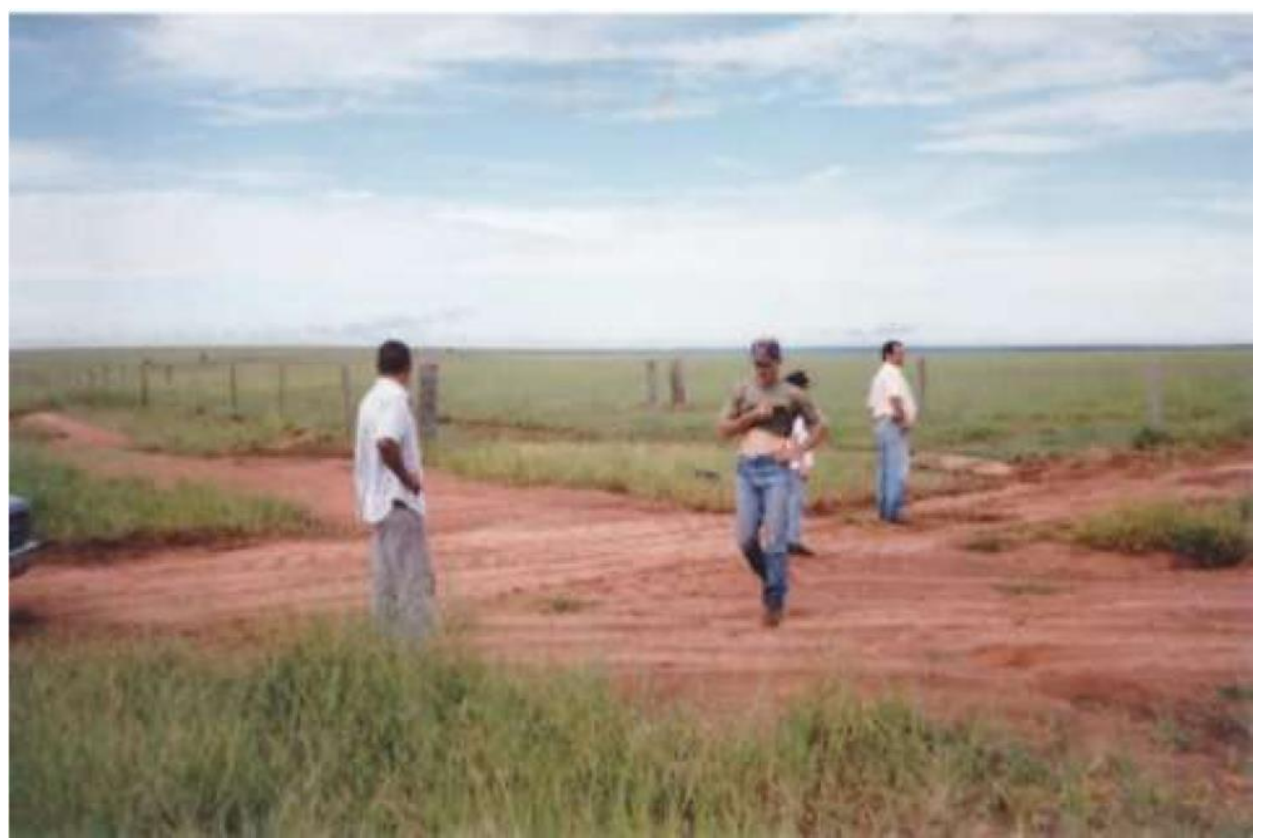

Figura 4: Reconhecimento da área dos lotes já sorteados e demarcados (1997). Fonte: Arquivo de Manoel Francisco Alves.

Após o sorteio dos lotes e seus devidos reconhecimentos por parte dos assentados, deu-se início, em 22 de Janeiro de 1997, à formação da comunidade PANA. Concretizou-se o sonho de 86 famílias de terem terra para plantar, morar e viver. Mas a luta não cessou, pois o desafio agora era superar as dificuldades de se manter em suas terras e de obter delas o seu sustento, principalmente pelas condições degradantes em que os solos se encontravam, pois a plantação de cana-de-açúcar da destilaria com o regime de monocultura destruiu grande parte das terras.

Posteriormente à concessão das terras reivindicadas pelos acampados que originou o assentamento PANA, surgiram outras três movimentações por terras próximas ao assentamento (o PAM, o Volta Redonda e o São João) e em todas as lutas os acampados obtiveram a vitória. Os novos assentamentos contribuíram para o crescimento populacional da região, a expansão territorial da Agrovila, estimulou o desenvolvimento e tornou a comunidade PANA um distrito de Nova Alvorada do Sul em Mato Grosso do Sul.

Atualmente, após vinte e quatro anos de assentamento, a agrovila tem se desenvolvido, ano após ano, contendo aproximadamente 500 residências. A luta, a resistência, trouxe às famílias a possibilidade de construir o seu espaço, conquistar a terra para viver e trabalhar, assim como de alcançar o objetivo de ter escola para os seus filhos.

\section{Do Tempo de Lona à Conquista da Escola}

Por meio dos depoimentos, pôde-se constatar que uma das dificuldades enfrentadas pelas famílias no acampamento era o difícil acesso à educação, pois as crianças eram transportadas em um caminhão até a cidade vizinha para frequentarem a escola, a qual era um anseio das famílias para que seus filhos pudessem estudar. A luta empreendida por escola revela a importância e a 
necessidade de instituições que sejam voltadas para as especificidades do campo, que possibilitem a essas crianças, aos jovens e adultos inserir-se na escolarização e, portanto, a educação é parte de seu projeto de vida. Na imagem 5 é possível perceber as dificuldades pelas quais as crianças e jovens enfrentavam para chegar até a escola e os pais para chegarem ao trabalho.

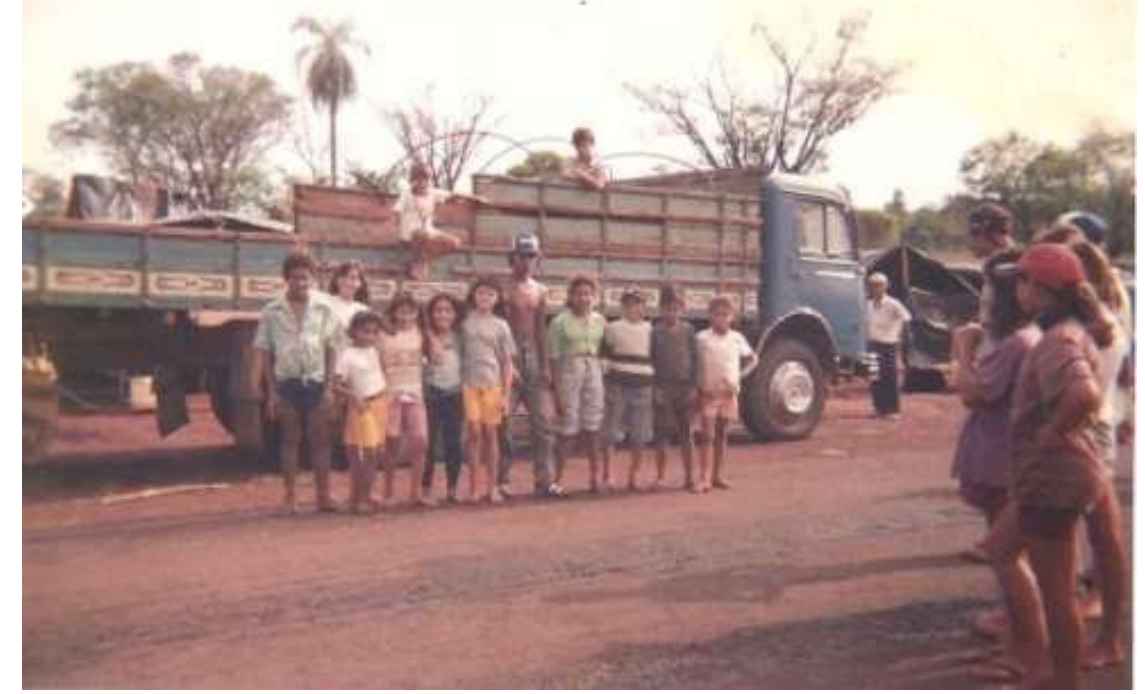

Figura 5: Transporte utilizado pelos assentados (1994.

Fonte: Arquivo de Manoel Francisco Alves.

Sobre a relação entre esse tempo de lona e a educação, destaca-se que, em 1995, por meio da CPT, começou a funcionar no acampamento uma sala de aula, conforme mostra a imagem 6 . As aulas eram ministradas pela professora Aparecida Bernardes, as instalações eram precárias, mas era uma possibilidade de abrigar as crianças e os jovens filhos dos trabalhadores que estavam nessa empreita em busca de uma vida digna com os seus direitos garantidos.

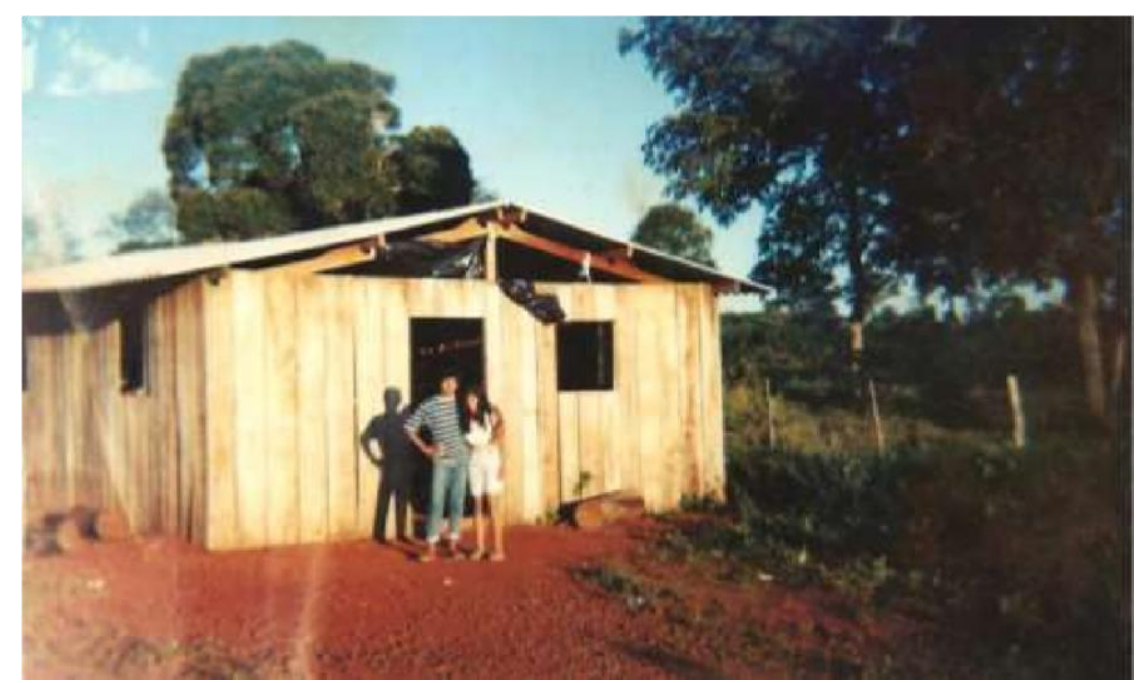

Figura 6: Sala de aula improvisada no acampamento em 1995. Fonte: Arquivo da Professora Aparecida Bernardes. 
Quando, em 1997, os acampados conseguiram a posse das terras e se mudaram para seus lotes, havia entre eles muitas crianças e jovens que precisavam dar continuidade aos seus estudos. Foi nesse momento que o prédio, antes destinado à usina, voltou a ser utilizado, agora como extensão da Escola Municipal Martinho Barbosa Martins. Inicialmente, a escola atendia as séries iniciais do ensino fundamental. Faziam parte de seu corpo docente três professoras: Maria Aparecida Marques Bernardi, Evanir Pereira da Silva e Márcia Andréia de Souza Molina.

À medida que o assentamento se desenvolveu, surgiu a necessidade de ampliação do prédio e, em 1999, a escola deixou de ser extensão da Martinho Barbosa Martins e passou a ser chamada de Comendador Luiz Meneghell, nome sugerido pelo vereador Dorival Barbosa em homenagem ao comendador parente do proprietário da antiga usina. O nome não foi aceito pela comunidade e, no ano de 2007, por sugestão do vereador Moisés Neres e por meio da Lei Municipal 355/07, de 16 de abril de 2007, o nome da instituição foi alterado para Escola Municipal Rosalvo da Rocha Rodrigues - RRR.

Rosalvo da Rocha Rodrigues era professor, pedagogo, pós-graduado em educação e com experiência em educação do campo. Sua atuação no processo de luta da constituição do acampamento PANA e posteriormente na feitura do assentamento foi de suma importância para a comunidade. Era militante da CPT, líder sindical e foi diretor da Escola Família Agrícola - EFA, que hoje recebe o seu nome e denomina-se Escola Família Agrícola Rosalvo da Rocha Rodrigues EFAR. Sua trajetória de vida foi marcada por sua importante participação na luta pela terra e por uma educação de qualidade para quem vive e trabalha no campo. Foi um dos mentores na implantação do ensino médio em escolas situadas nos assentamentos.

Conforme mostra a imagem 8, no assentamento há a escola municipal RRR e o Centro Municipal de Educação Infantil - CEMEI- Maria Aparecida Medeiros Alves, que atende aproximadamente 600 crianças e jovens. A escola possui uma quadra de esportes comunitária, uma praça contendo pista de caminhada e academia ao ar livre, além de um posto de saúde e alguns comércios no seu entorno.

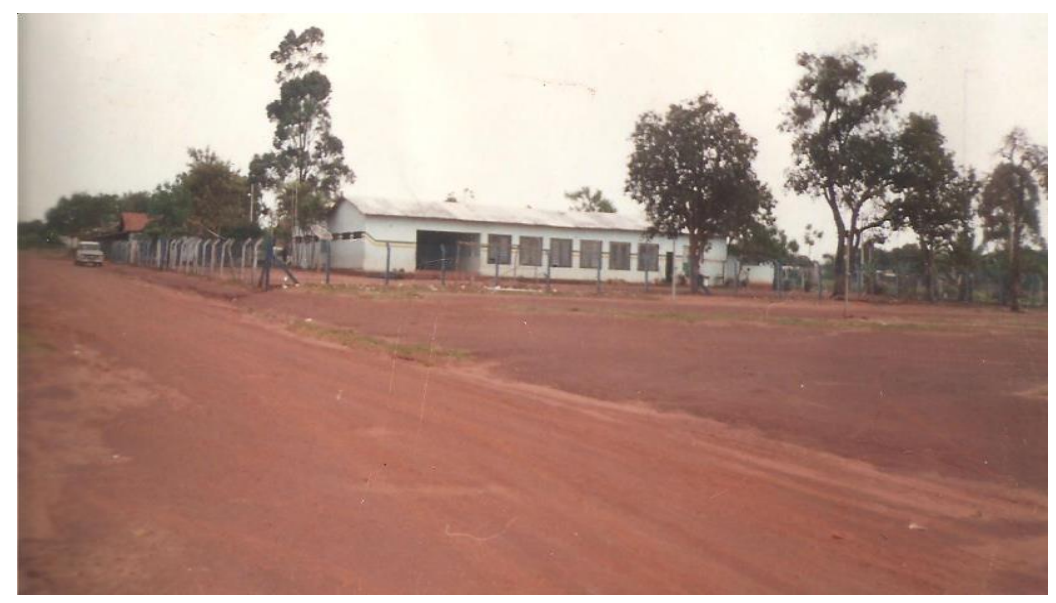

Figura 7: Escola Rosalvo da Rocha Rodrigues 1999.

Fonte: Arquivo da escola. 
Os estabelecimentos no entorno da escola são frequentados por assentados e também por moradores de várias fazendas vizinhas. A subsistência das famílias do assentamento provém, principalmente, da prestação de serviço para usinas da região, seguindo da renda dos lotes e de seus comércios particulares, o que sinaliza que há muito ainda a ser conquistado no âmbito de uma Reforma Agrária camponesa nessa região.

A escola RRR é oriunda da luta e resistência dos camponeses, está localizada no campo e atende os filhos dos camponeses, mas em sua documentação não consta ainda que é uma escola do campo. Essa realidade apresenta um desafio: a tarefa de lutar para que o ensino da escola seja de qualidade e embasado nos fundamentos da educação do campo, respeitando a realidade dos alunos e valorizando a cultura camponesa, a história do assentamento.

Desse modo, a luta empreendida pelos trabalhadores não pode e não deve ser excluída no interior da escola do campo, mas sim fazer parte de seu projeto pedagógico com sentido de favorecer que os estudantes se reconheçam na sua história e na luta de seus familiares e de sua comunidade, para que os direitos sejam garantidos, principalmente o direito à educação escolar.

\section{Considerações Finais}

Em contato com as entrevistas dos assentados foi possível compreender que a trajetória de luta pela terra e por uma vida de qualidade proporcionou aos acampados momentos de muito sofrimento e de diversas necessidades. Entretanto, após vários entraves, as barreiras foram rompidas e as terras desapropriadas, realizando o sonho de 86 famílias que lutavam em busca do seu "pedaço de chão".

Os povos do campo são sujeitos históricos, suas lutas ainda se fazem presentes na memória e na construção do assentamento em pauta. As lutas são compartilhadas com movimentos e organizações que buscam contribuir para que os trabalhadores conquistem os seus direitos. Para a garantia desses direitos, eles ocupam, fazem marchas, unem forças e coragem para a conquista de uma vida digna juntamente com as suas famílias.

Em meio a essas lutas, a escola se faz presente, é uma conquista. Por isso, essa luta é uma tarefa de todos que batalham por educação de qualidade, que inclua, agregue e possibilite a transformação para uma sociedade mais justa, na qual todos usufruam de seus direitos, dentre eles uma educação humana e socialmente referenciada por seus grupos de direito.

É nesse sentido que a escola do campo "[...] pode ser parte importante das estratégias de desenvolvimento rural, mas para isto precisa desenvolver um projeto educativo contextualizado, que trabalha a produção do conhecimento a partir das questões relevantes para intervenção social nessa realidade". (FERNANDES, CERIOLI; CALDART, 2009, p. 52).

Importante afirmar que a escola está organicamente vinculada ao espaço onde está inserida, por isso é vital compreender os ideários da classe trabalhadora junto aos movimentos sociais em defesa do direito de todos os povos do campo à educação e, portanto, à escola de qualidade no campo. 


\section{REFERÊNCIAS}

BRASIL, LDB. Lei 9.394. Lei de Diretrizes e Bases da Educação Nacional, de 20 de dezembro de 1996. Disponível em:

http://portal.mec.gov.br/seesp/arquivos/pdf/lei9394_ldbn1.pdf. Acesso em: 20 abr. 2021.

BRASIL. Resolução CNE/CEB n¹, de 3 de abril de 2002. Conselho Nacional de Educação - Câmara de Educação Básica. Diretrizes Operacionais para a Educação Básica nas Escolas do Campo. Seção 1, p. 32. Brasília: Diário Oficial da União, 9 abr. 2002. Disponível em:

http://portal.mec.gov.br/index.php?option $=$ com_docman\&view=download\&alia $\mathrm{s}=13800$-rceb001-02-pdf\&category_slug=agosto-2013-pdf\&Itemid=30192.

Acesso em: 20 abr. 2021.

BRASIL. Decreto no 7352, de 4 de novembro de 2010.Política de Educação do Campo e o Programa Nacional de Educação na Reforma Agrária (PRONERA). Brasília: Diário Oficial da União, 5 nov. 2010. Disponível em: http://portal.mec.gov.br/docman/marco-2012-pdf/10199-8-decreto-7352-de4de-novembro-de-2010/file. Acesso em: 20 abr.2021.

CALDART, Roseli Salete. Elementos para construção do Projeto PolíticoPedagógico da Educação do Campo. In: MOLINA, Mônica Castagna; JESUS, Sônia Meire Azevedo de (Orgs.). Por Uma Educação do Campo:

Contribuições para um projeto de Educação do Campo. Brasília, DF:

Articulação Nacional "Por Uma Educação do Campo", 2004. Coleção Por Uma Educação do Campo, no 5. p. $10-31$.

CALDART, Roseli Salete. A escola do campo em movimento. In: ARROYO, Miguel Gonzáles; CALDART, Roseli Salete; MOLINA, Monica Castagna. (Org.).

Por uma Educação do Campo. Petrópolis, RJ: Vozes, 2009.

CANUTO, Antonio. Comissão Pastoral da Terra (CPT). In: CALDART, Roseli Salete; PEREIRA, Isabel Brasil; ALENTEJANO, Paulo; FRIGOTTO, Gaudêncio.

Dicionário da Educação do campo. $3^{a}$. Ed. Rio de Janeiro, São Paulo: Escola Politécnica de Saúde Joaquim Venâncio, Expressão Popular, 2013. p.129-133.

FERNANDES, Bernardo Mançano; CERIOLI, Paulo Ricardo; CALDART, Roseli Salete. "Primeira Conferência Nacional 'Por uma educação básica do campo': texto preparatório". In: ARROYO, Miguel Gonzalez; CALDART, Roseli Salete; MOLINA, Mônica Castagna. Por uma educação do campo. Petrópolis: Vozes, 2009.

FERNANDES, Bernardo Mançano. Movimento dos Trabalhadores Rurais sem Terra (MST). In: CALDART, Roseli Salete; PEREIRA, Isabel Brasil; LENTEJANO, Paulo; FRIGOTTO, Gaudêncio. Dicionário da Educação do campo. $3^{a}$. Ed. 
Rio de Janeiro, São Paulo: Escola Politécnica de Saúde Joaquim Venâncio, Expressão Popular, 2013.p.496-507.

FERNANDES, Bernardo Mançano. Movimentos socioterritoriais e movimentos socioespaciais: contribuição teórica para uma leitura geográfica dos movimentos sociais. Revista NERA-Ano 8, n. 6 - Janeiro/Junho de 2005. Disponível em: http://www2.fct.unesp.br/nera/revistas/06/Fernandes.pdf. Acesso em 03 abr. de 2021.

KOLLING, Jorge Edgar; VARGAS Cristina Maria; CALDART, Roseli Salete. MST e Educação. In: CALDART, Roseli Salete; PEREIRA, Isabel Brasil; ALENTEJANO, Paulo; FRIGOTTO, Gaudêncio. Dicionário da Educação do campo. $3^{a}$. Ed. Rio de Janeiro, São Paulo: Escola Politécnica de Saúde Joaquim Venâncio, Expressão Popular, 2013.p.501-507.

LEITE, Sergio Pereira; MEDEIROS, Leonilde Servolo. Agronegócio. In: CALDART, Roseli Salete; PEREIRA, Isabel Brasil; ALENTEJANO, Paulo; FRIGOTTO, Gaudêncio. Dicionário da Educação do campo. 3a. Ed. Rio de Janeiro, São Paulo: Escola Politécnica de Saúde Joaquim Venâncio, Expressão Popular, 2013.p.79-85.

MELO, Danilo Souza. A luta pela terra em Mato Grosso do Sul: o MST e o protagonismo da luta na atualidade. Revista NERA, Presidente Prudente, Ano 20, no. 39 p. 133-160 2017. Disponível em:

https://revista.fct.unesp.br/index.php/nera/article/view/4204/3971. Acesso em: 10 mar. 2021.

MOLINA Mônica Castanha; SÁ, Lais Mourão. Escola do Campo. In: CALDART, Roseli Salete; PEREIRA, Isabel Brasil; ALENTEJANO, Paulo; FRIGOTTO, Gaudêncio. Dicionário da Educação do campo. 3a. Ed. Rio de Janeiro, São Paulo: Escola Politécnica de Saúde Joaquim Venâncio, Expressão Popular, 2013.p.324-331.

PEREIRA, Monica Cox de Britto. Revolução verde. In: CALDART, Roseli Salete; PEREIRA, Isabel Brasil; ALENTEJANO, Paulo; FRIGOTTO, Gaudêncio.

Dicionário da Educação do campo. 3a. Ed. Rio de Janeiro, São Paulo: Escola Politécnica de Saúde Joaquim Venâncio, Expressão Popular, 2013.p.685-689.

PIRES, Angela Monteiro. Educação do campo como direito humano. São Paulo: Cortez Editora, 2012.

ROSA, Marcelo Carvalho. Ocupações de terra. In: CALDART, Roseli Salete; PEREIRA, Isabel Brasil; ALENTEJANO, Paulo; FRIGOTTO, Gaudêncio.

Dicionário da Educação do campo. 3a. Ed. Rio de Janeiro, São Paulo: Escola Politécnica de Saúde Joaquim Venâncio, Expressão Popular, 2013.p.509-512. 
SOUZA, Antônia Maria; CRUZ Rosana Aparecida da. Educação do campo e escola pública: experiência e resistência. Revista debates insubmissos, Caruaru, PE. Brasil, Ano 1, v.1, no 3, set/dez. 2018. Disponível em:

https://periodicos.ufpe.br/revistas/debatesinsubmissos/. Acesso em: 15 mar. 2021.

STEDILE, João Pedro. Questão Agrária. In: CALDART, Roseli Salete; PEREIRA, Isabel Brasil; ALENTEJANO, Paulo; FRIGOTTO, Gaudêncio. Dicionário da Educação do campo. $3^{a}$. Ed. Rio de Janeiro, São Paulo: Escola Politécnica de Saúde Joaquim Venâncio, Expressão Popular, 2013.p.639-644.

WELCH, Andrew Clifford. Conflitos no campo In: CALDART, Roseli Salete; PEREIRA, Isabel Brasil; ALENTEJANO, Paulo; FRIGOTTO, Gaudêncio.

Dicionário da Educação do campo. $3^{a}$. Ed. Rio de Janeiro, São Paulo: Escola Politécnica de Saúde Joaquim Venâncio, Expressão Popular, 2013.p.141-157.

Recebido em: 4 de junho de 2021. Aceito em: 10 de setembro de 2021. Publicado em: 15 de dezembro de 2021. 